\title{
A voz da cidade portuária: a presença do porto urbano em Vitória / ES"1
}

Flavia Nico Vasconcelos*

\begin{abstract}
Resumo
As cidades portuárias são marcadas por relações peculiares que se desenvolvem entre cidade e porto. Essas relações são mantidas historicamente quando cidade e porto mantêm interdependências ou reproduzem socialmente identidades e culturas criadas a partir da trajetória comum. Há casos em que porto e cidade seguem rumos diferentes e muito pouco do ser cidade portuária permanece na memória e no sentimento dos seus habitantes. Este artigo é resultado de pesquisa de campo realizada na cidade portuária de Vitória/ES. Ao ouvir os moradores e comerciantes que vivem no entorno do Porto de Vitória, percebemos que a natureza de ser cidade portuária está sendo perdida.
\end{abstract}

\section{Palavras-chave}

Cidades portuárias. Interfaces cidade-porto. Vitória/ES.

\begin{abstract}
Port cities are known for its special relations due to the interfaces between city and port. Those interfaces are historically sustained when both city and port keep growing and developing together and fostering its interdependence through the creation of identities and cultural aspects that resemble its common trajectory. There are cases when city and port follow different ways of development and the connections that sustained the port city as one single unity is kept only in the memory and nostalgic feelings of its inhabitants. This paper is the result of a field research that studied the trajectory of the port city of Vitoria/ES - Brazil and how the perception of being a port city has been lost by its inhabitants.
\end{abstract}

\section{Keywords}

City port. City port interfaces. Vitória/ES.

\footnotetext{
${ }^{1}$ Pesquisa financiada pela Fundação Nacional de Desenvolvimento do Ensino Superior Particular (FUNADESP) em 2012. Participaram da pesquisa de campo os alunos de iniciação científica Roberta Ferro, Patricia Canci, Ana Luiza Pena e Romilson Neto.

* Doutora em Ciências Sociais pela Pontifícia Universidade Católica de São Paulo (PUC-SP); professora do curso de mestrado em Sociologia Política e da Faculdade de Relações Internacionais da Universidade de Vila Velha (UVV) / Espírito Santo. E-mail: flavia.nico@yahoo.com.
} 


\section{Apresentação}

Tradicionalmente, as cidades portuárias vivem uma relação histórica, complexa e de interdependência entre cidade e porto. Em alguns casos, os portos que perderam sua capacidade competitiva e contam com espaços ociosos ou áreas degradadas têm esses espaços recuperados para uso urbano a partir de projetos de reconversão de seus waterfronts - como em Boston, Baltimore, Lisboa, Buenos Aires, Belém, dentre outros.

Há outros casos, em que as cidades convivem com seu antigo porto urbano apenas porque seguem localizados em sítios centrais, sem que com ele mantenham uma relação simbiótica, vinculação econômica direta ou mesmo identidade histórico-patrimonial - como em Barcelona, Antuérpia, Rio de Janeiro e Santos. Nesses casos, em algum momento, a função portuária se distanciou das atividades urbanas e segue como um equipamento da cadeia logística ainda localizado no centro dinâmico urbano. O referencial de ser cidade portuária é comumente perdido, as necessárias interações com o porto urbano tendem a acontecer de forma conflituosa, e a percepção da comunidade sobre a presença do porto recai sobre seus aspectos negativos insegurança, foco de prostituição, barreira visual ao mar, estética desagradável, dentre outras.

Em Vitória/ES, a presença de um complexo portuário relativizou a importância de seu primeiro porto - o Porto de Vitória. A ausência de políticas públicas que tratem a cidade como cidade portuária e fortaleçam a identidade do porto urbano como bem cultural e patrimonial favoreceu olhar para o Porto como mera porta de entrada e saída de mercadorias ou como lugar isolado onde se desenvolvem atividades com fins econômicos.

Localizado no que hoje é o centro histórico da cidade (ou "Centro") e outrora foi o núcleo de desenvolvimento econômico da capital, o Porto de Vitória ocupa área urbana ao longo da baía da ilha de Vitória, em trecho utilizado como via de passagem de grande fluxo de veículos na transição entre as cidades vizinhas de Vitória/Cariacica/Vila Velha e aproveitando-se de espaço nobre e histórico em frente à sede do governo estadual - o Palácio Anchieta.

Vitória ainda é uma cidade portuária? Respondemos a essa pergunta a partir das percepções daqueles que têm o Porto de Vitória em seu dia a dia - os moradores e comerciantes do entorno portuário. A pesquisa analítica utilizou-se de metodologia hipotético-dedutiva, estudo de bibliografia primária e secundária sobre Vitória e literatura especializada em cidades 
portuárias. Sua principal contribuição é fruto da realização de estudo de campo através da aplicação de questionários estruturados que dão voz a moradores e comerciantes do entorno do Cais Comercial do Porto de Vitória ${ }^{2}$.

\section{A evolução histórica da interface cidade-porto em Vitória/ES}

O conceito de cidade portuária não é consensual e caracteriza-se pelo seu sincretismo (DUCRUET, 2005; WANG; OLIVIER, 2003). Da dificuldade em encontrar um ponto que dê a especificidade do objeto cidade portuária e que aponte o que lhe é peculiar, Ducruet (s/d) parte para aquilo que a distingue: os portos sem cidade e as cidades sem porto. Afinal, nem todos os portos estão associados a uma cidade e nem toda cidade com um porto mantém com ele uma relação de proximidade.

O termo cidade porto (port city ou ville portuaire) refere-se a uma cidade portuária onde houve um porto, agora desaparecido ou inoperante, ou que guarda traços derivados da presença de um porto sem que mantenha com ele uma relação de proximidade (HENRY, 2006). Já o termo cidade portuária (cityport ou ville port) está relacionado a uma cidade efetivamente dotada de um porto urbano em operação. No primeiro, há uma ideia de justaposição e imbricação; no segundo, de interação, complementaridade e interligação.

Para Hoyle (1997/98), a ideia de cidade portuária é derivada da associação tradicional e íntima entre cidade e porto, que é seu maior componente. Brian Hoyle (1989) ${ }^{3}$ propõe um modelo de evolução da cidade portuária industrial ocidental composto por cinco fases de modificações nas relações de interação, complementaridade e interligação entre cidade e porto. Conseguimos utilizar esse modelo, com ajustes nos períodos históricos, para descrever a evolução da cidade e do porto urbano de Vitória/ES.

A história da cidade de Vitória se confunde com a história de seu porto urbano no longo período do século XVI até 1930/40. Durante todo esse tempo, a cidade e porto desenvolvem-se mutuamente em uma relação

\footnotetext{
${ }^{2}$ Além do Cais Comercial e do Terminal Flexibrás/Technip, que ficam do lado da baía em Vitória, o Porto de Vitória conta com seis cais ou terminais em Vila Velha.

${ }^{3}$ Outras propostas de compreensão das relações cidade e porto podem ser encontradas em Hoyle (1997/98), Ducruet (2010), Bird (1963), Gravari-Barbas (1996), Norcliff et al (1989), Henry (2006) e Pinder et al. (1988).
} 
simbiótica, que pode ser identificada com o que Hoyle (1989) classificou como etapa Porto-Cidade Primitivos, a primeira fase do modelo.

Uma retrospectiva histórica nos permite afirmar que a cidade nasce, em 1535, pretendendo ser cidade portuária. Um dos motivos da escolha da então vila de Vitória como sede da capitania do ES foi as boas condições de sua baía para o desenvolvimento da atividade portuária. A organização portuária acompanha o crescimento e urbanização da cidade. Os relatos dos presidentes da província no século XIX mencionam as obras de construção do porto de maneira associada à construção e urbanização da cidade (VASCONCELOS, 2011). Do período de fundação da cidade até 1928, o Porto fez parte dos planos da gestão pública junto aos planejamentos para construção da infraestrutura física da cidade - construção de avenidas, urbanização dos lugares, melhoria da qualidade de vida (SIQUEIRA; VASCONCELOS, 2012).

A função portuária também estava em sintonia com as atividades econômicas urbanas. Os diversos cais, que posteriormente deram lugar ao porto organizado, estavam associados às atividades da sociedade local - como o Cais Grande, construído com finalidades comerciais, e o Porto dos Padres, que atendia aos jesuítas e às populações que traziam lavoura do interior. A relevância do Porto foi estratégica no século XIX para o desenvolvimento local a partir do escoamento dos produtos de Minas Gerais, estado vizinho sem acesso ao mar, e no século XX, para consolidação da cidade como capital. A atividade da produção do café para exportação foi, por décadas, a base da economia local e, assim, estava diretamente associada à existência do Porto para seu escoamento.

A projeção comercial do Porto de Vitória oficialmente organizada ocorre em 1940, com a conclusão do seu aparelhamento pautado no incremento dos sistemas de transportes marítimo e terrestre. Até essa época, pensar a cidade era pensar o porto e vice-versa.

É a partir do governo interventor de Punaro Bley (1930/43) que identificamos os primeiros sinais de que as preocupações da cidade, agora voltadas para as necessidades sociais de seus habitantes, se desvinculam da construção do Porto, por sua vez mais associado à pauta de exportações, diversificação de atividades e demandas do transporte marítimo. O perfil do Porto muda com a transformação da base econômica primário-exportadora para a economia urbano industrial, e a perspectiva de exportação de minério de ferro leva a uma trajetória expansionista da hinterlândia e da estrutura física portuária (SIQUEIRA, 1995).

Cada vez menos o Porto de Vitória é visto como parte da urbe, tem seu 
crescimento vinculado ao dela e é tido como instrumento para atingir metas vinculadas a interesses locais. Entramos na segunda etapa do modelo de Hoyle (1989), Porto-Cidade em Expansão. O modelo prevê o rápido crescimento comercial/industrial da cidade e forças que impelem o porto a desenvolver-se além do limite da cidade, com cais linear e indústrias de carga fracionada.

A expansão física do Porto para território continental, do outro lado da Baía de Vitória, em Vila Velha, acontece a partir da década de 1950. Primeiro, o novo cais, situado na base do morro de Atalaia, com três terminais para armazenamento e descarregamento de derivados de petróleo a granel. A seguir, o cais de Paul, também em Vila Velha, em área já provida de ligação rodoferroviária, para atender ao fluxo de minério fino (CAMPOS, 2004). Assim, até mesmo a interface física do Porto com a cidade passa a ser relativizada frente ao crescimento em direção ao continente.

Para atender à indústria do aço e aos grandes projetos industriais que chegavam ao ES, as instalações portuárias são progressivamente transferidas para fora do centro urbano da capital, como Porto de Tubarão (1966) e de Praia Mole (1984), e posteriormente totalmente afastadas da conurbação metropolitana, como Portocel/Aracruz (1978) e Porto de Ponta de Ubu/ Ubu (1977).

A expansão física do novo complexo portuário é reflexo da inserção definitiva da economia capixaba no processo de industrialização e da mudança da dinâmica urbana e econômica da cidade. É nas décadas de 1970 e 1990 que verificamos o distanciamento cidade e Porto de Vitória. E é a partir desse momento que a cidade atrapalha o Porto e vice-versa.

Identificamos aqui a sobreposição da terceira e quarta fases do modelo de Hoyle (1989). Na terceira fase, o crescimento da indústria e a introdução dos contêineres impõem aos portos a necessidade de mais espaços - Porto-Cidade Industrial Moderno. Já na quarta fase, Recuo das Frontes Marítimas, as mudanças na tecnologia marítima induzem o crescimento das áreas de desenvolvimento industrial e marítimas separadas da cidade.

Destaca-se a desassociação da função portuária das atividades econômicas da cidade de Vitória. O Porto de Vitória passa a buscar a diversificação da pauta de comércio exterior, de maneira que muitos dos produtos que passam por ele não têm nem origem e nem destino o ES. A cidade se urbaniza, cresce economicamente e aumenta sua população. O Porto desenvolve sua atividade-fim e cresce fisicamente. A industrialização move as duas partes para o crescimento e semeia a expansão urbana e portuária no Estado. Com a industrialização, Vitória se torna ponto central da Região Metropolitana da 
Grande Vitória e o Porto de Vitória é inserido num conjunto de outros portos que se destacam tanto ou mais do que ele. O dinamismo do crescimento urbano amplia a escala da cidade e a insere em um todo maior, e o mesmo acontece com o porto urbano, agora parte de um complexo portuário estadual.

A presença do porto urbano associou a navegação ao comércio e a associação destes à atividade econômica deram a Vitória um aspecto que no decorrer dos anos consagrou-se como vocação portuária. A formação de um complexo portuário composto por 6 portos e terminais alia a percepção dos portos como interface física de deslocamento, isto é, embarque e desembarque de cargas e pessoas, com uma nova visão do porto como polo de atração de atividades econômicas, um agente econômico, elo de cadeia logística e interface física (CAMPOS, 2004). A vocação portuária vincula-se exclusivamente às facilidades logísticas para empresas de comércio exterior e ao desenvolvimento econômico desencadeado por essas empresas. Não está atrelada à valorização do patrimônio portuário ou à perpetuação de uma identidade marítimo-portuária alimentadas por tradição ou por políticas públicas.

Na década de 1990, com sua lógica apartada da lógica urbana, a urbe se torna um empecilho ao bom funcionamento das operações e atividades portuárias. As mudanças no funcionamento do Porto passam a requerer mais espaços para acomodação de contêineres, águas com grande profundidade para navios gigantescos, corredores de transportes livres e com funcionamento 24 horas, dentre outras.

Também o porto atrapalha a cidade. O acesso e a vista para o mar tornamse desejo dos habitantes da cidade, o que é impedido pelos muros do Porto; os espaços situados nos centros urbanos ganham valorização imobiliária, e os grandes sítios dos portos viram alvo do interesse de construtoras; a presença do porto é associada, em geral, a muita atividade durante o dia, com circulação de trabalhadores e caminhões, que atrapalham a mobilidade urbana, e de isolamento à noite, com muros altos, sujos, escuros e estimulantes às casas de prostituição. O porto urbano se torna uma pedra no caminho da cidade, que evolui em busca de melhor qualidade de vida de seus habitantes.

Uma nova fase, a quinta etapa do modelo de Hoyle (1989) aposta na reaproximação espacial cidade e porto em novos moldes. Como o porto moderno, os navios gigantes e a conteinerização passaram a exigir espaços amplos, os portos tendem a migrar para locais afastados do centro urbano e liberam espaços centrais que podem ser aproveitados para uso urbano. No 
urbanismo ganha força o movimento dos waterfronts, que sugere que zonas portuárias em áreas urbanas sejam reconvertidas em espaços que valorizem o patrimônio histórico-portuário na forma de equipamentos de lazer para usufruto da cidade.

O debate sobre o futuro do Porto de Vitória começou primeiramente no âmbito acadêmico em meados de 1990. Professores do curso de Arquitetura e Urbanismo da UFES colaboraram para a elaboração de documentos e planos estratégicos para o setor público a partir das ideias do movimento dos waterfronts. A nova interpretação de reconversão dos espaços portuários, entretanto, não agradou a toda comunidade portuária (SOARES; LIMA Jr, 2005).

A polarização aconteceu entre o poder público local - a Prefeitura Municipal de Vitória (PMV) - e Autoridade Portuária - a CODESA. A PMV, no governo de Luis Paulo Velloso Lucas (1997-2005), apostou no fim da vida útil do Porto, e nos projetos de revitalização do Centro propôs a transformação de seus armazéns em centros de lazer e turismo. O projeto Vitória do Futuro destacava o Porto como marco histórico referencial nos planos de revitalização do Centro e apostava na recuperação da identidade da região a partir de suas vantagens paisagísticas e naturais. Sem uma posição consensual, alguns funcionários da CODESA reconhecem que o Porto de Vitória é inadequado para as atividades portuárias modernas e deve ser substituído por outro porto longe da capital, enquanto outro grupo defende que o Porto está em plena atividade, atuando no apoio logístico à exploração de petróleo off shore (PRATA, 2010; BRECIANI, 2010).

É somente com a troca de governo local e o recuo nas propostas do poder público de reconversão dos espaços portuários para uso urbano que o diálogo se restabelece (ZIMMER, 2010; PMV, 2010). Outros dois eventos vieram a impulsionar a reaproximação cidade e porto em Vitória: (a) a Lei 8.630/93, Lei de Modernização dos Portos, criou o Conselho Administrativo Portuário/CAP, com representantes do poder público, operadores portuários, trabalhadores portuários e usuários dos serviços portuários, e assim estabeleceu um fórum permanente de negociação; e (b) a realização da oficina internacional Les Ateliers, que trouxe as diferentes partes e arquitetos e estudiosos internacionais para um workshop no qual se discutiu a interface cidade-porto e grupos de trabalho apresentaram propostas diferentes para melhorar sua relação. O Les Ateliers é marco fundamental na reaproximação cidade e Porto de Vitória e tem papel central em colocar na agenda da PMV e da CODESA a necessidade de diálogo para assuntos que ainda são comuns 
ou de interesse mútuo (BRECIANI, 2010).

Uma sexta etapa ao modelo de Hoyle (1989) é adicionada por Henry (2006), a Renovação dos laços cidade-porto (1980-2000), que prevê novas associações cidade-porto e estreitamento da integração entre eles. Após período de distanciamento e conflito na relação porto urbano e cidade, a tendência atual nas cidades portuárias é de harmonizar a convivência do porto com a cidade; isto é, buscar formas para que seja possível conservar a presença do porto na cidade.

Essa é a realidade atual de Vitória. Se, por um lado, verificamos que as relações entre a cidade e a CODESA passam longe do consenso; por outro, é importante destacar o restabelecimento do diálogo e das tentativas de se chegar a um denominador comum a partir de 2000. A CODESA tem demonstrado esforços para acomodar as necessidades de reforma para modernização dos espaços portuários em sintonia com as necessidades de mobilidade urbana de Vitória (BRECIANI, 2010). A PMV, por sua vez, tem realizado ações de revitalização das calçadas, muros e armazéns do Porto e implementado políticas pontuais objetivando aproximar o Porto da população (MENEGHEL, 2010).

Para além dos desafios que a presença do porto urbano e da cidade representam um para o outro, os atuais representantes e gestores da PMV e da CODESA resgataram a percepção de que há interesses comuns e que o diálogo e a parceira são as saídas para uma coexistência harmoniosa na histórica interface cidade e porto de Vitória (MENEGHEL, 2010; BRECIANI, 2010; ZIMMER, 2010). O centro histórico e o Porto de Vitória fazem parte de políticas e ações isoladas da Secretaria de Turismo/PMV - para atração de cruzeiros e definição de rotas turísticas no centro histórico - e da Secretaria de Desenvolvimento da Cidade/PMV - para revitalização do Centro.

Presencia-se, atualmente, um posicionamento contraditório entre Secretaria de Transportes e Obras Públicas e Conselho Estadual de Cultura/ Secretaria de Cultura do governo do Estado. A primeira prevê a passagem de corredores de ônibus do projeto BRT dentro dos armazéns portuários. A segunda apresentou, desde 2011, projeto para tombamento desses armazéns como patrimônio histórico-cultural, e seus conselheiros têm se aproximado da sociedade civil organizada, que reclama da perda do espaço cultural Estação Porto no Armazém 5.

No cenário atual, a ausência de uma política pública mais ampla e consistente que envolva as diferentes secretarias municipais em projetos que tenham como norte comum a projeção do Porto como bem cultural e 
paisagístico e que resgatem o sentimento e identidade de ser cidade portuária impacta nas possibilidades de avanços no diálogo entre as partes.

\section{A interface cidade-porto em Vitória/ES na percepção dos moradores e comerciantes do entorno portuário}

A percepção do pesquisador da interface cidade-porto em Vitória é de que não mais se olha, não mais se pensa e muito menos se age como se Vitória fosse uma cidade portuária. Parece que o Porto se perdeu da cidade ou a cidade perdeu o referencial de seu Porto. Em busca da verificação dessa hipótese, ouviu-se a opinião daqueles que vivem na cidade e têm o Porto presente, fisicamente, em seu dia a dia: moradores e comerciantes do entorno do Cais Comercial.

A amostra foi calculada a partir da população de eleitores do Centro (8670 hab.), com margem de erro de $9 \%$ e $95 \%$ de confiabilidade. No total, foi aplicado aleatoriamente um único modelo de questionário estruturado a 110 moradores e/ou comerciantes, sendo 51 moradores e 59 comerciantes e, desses, 42 mulheres e 68 homens.

Por entorno portuário consideramos os espaços imediatamente em frente ao Porto, bem como a região comercial central do Centro de Vitória (Cidade Alta e arredores da Catedral e Praça Costa Pereira). O Porto ocupa uma área de mais ou menos 1,3 km desde a Vila Rubim até o começo da Av. Beira Mar, passando pelas Avenidas Elias Miguel e Presidente Getúlio Vargas e chegando até o começo da Av. Marechal Mascarenhas. A linha divisora entre o Porto e a cidade é quase toda marcada pelas paredes dos armazéns e demais edificações. São raros os vãos abertos, e contam sempre com grades ou muros.

Para a elaboração do questionário, utilizamos documento da Rede Mundial de Cidades Portuárias/AIVP, que sugere medidas de boas práticas para melhorias na interface cidade e porto. $\mathrm{O}$ documento apresenta cinco dimensões a serem trabalhadas: integração dos espaços, da dimensão urbana, das funções, do meio ambiente e da sociedade.

Elegemos como aspecto a ser investigado a dimensão urbana. O questionário de perguntas foi elaborado para obter a percepção e opinião de moradores e comerciantes sobre os três aspectos que deveriam ser atendidos para boas práticas nesta dimensão, quais sejam: (a) tratar o porto como espaço urbano, zelando pela arquitetura de qualidade e cuidando dos elementos separadores 
cidade e porto; (b) tornar o porto visível pela combinação da redução do visual poluidor do porto com aberturas para a água e para ele próprio; (c) explorar as potencialidades da água, usando saídas para a água como meios para uma transição suave da cidade para o mar, compartilhando o uso da água, favorecendo o deslocamento dos habitantes por ela e movendo a cidade em direção ao porto através da água.

Primeiramente, questionamos a população sobre a percepção que têm da presença física do Porto. Buscou-se identificar se percebem as construções portuárias como parte da paisagem da cidade, se têm posicionamento crítico em relação à qualidade de conservação desses espaços e se os elementos separadores entre cidade e porto - as grades e muros - são necessários ou poderiam permitir maior integração do cidadão com a Baía de Vitória.

Identificou-se que $75 \%$ dos entrevistados percebem os armazéns e edifícios do Porto como parte integrante da paisagem da cidade. Cabe destacar que a percepção é mais forte por parte dos comerciantes $(81 \%)$ do que pelos moradores (68\%). Essa é uma tendência identificada no decorrer da análise dos dados coletados. Metade dos entrevistados concorda que a existência do Porto contribui positivamente para a paisagem do Centro; os demais dividem-se entre aqueles que acreditam que a contribuição é negativa $(26 \%)$ ou indiferente $(22 \%)$. Se nos aprofundarmos na percepção negativa, verificamos que a quantidade de moradores $(29 \%)$ que percebe a presença das construções do Porto de forma negativa é maior do que a de comerciantes $(24 \%)$.

Em relação às fachadas e conservação do espaço portuário, a maioria reclama da má conservação da pintura e da estrutura física portuária, sobretudo dos prédios (69\%) e calçadas $(71 \%)$. O descontentamento com as calçadas e ciclovias parte sobretudo dos moradores, dos quais $82 \%$ afirmam que as mesmas não atendem satisfatoriamente às suas necessidades. Vale destacar que os comerciantes $(81 \%)$ são mais incisivos do que os moradores (65\%) em relação à má conservação das fachadas. Ainda, 12\% dos moradores nunca pararam para observar as fachadas do Porto, percentual que cai para $4 \%$ quando falamos com os comerciantes.

O muro que separa o Porto da cidade - e é tanto uma barreira visual para a Baía de Vitória, quanto uma medida de segurança para a atividade portuária - é percebido por $78 \%$ dos entrevistados como sendo necessário. Para 36\% dos moradores o muro é necessário, mas deveria permitir uma maior integração dos moradores e passantes com a Baía. Apenas $7 \%$ dos comerciantes têm essa visão, $27 \%$ não têm opinião definida em relação ao 
muro e $51 \%$ entendem que não teria como ser diferente por uma questão de segurança. O posicionamento dos comerciantes é mais pragmático e associado à atividade-fim do negócio portuário, o posicionamento do morador é o do cidadão que deseja usufruir da natureza que a cidade lhe oferece.

Em suma, a infraestrutura física portuária é percebida como integrada à paisagem e vida da cidade e, talvez pela identificação da prática econômicocomercial e da presença física do porto impactar no ambiente local de negócios, os comerciantes demonstram maior interesse, conhecimento e apresentam posicionamento mais crítico do que os moradores. A conclusão surpreende pelo perfil dos moradores do Centro, marcado por alto índice de envelhecimento, 6o bairro mais populoso de Vitória, sem relevante crescimento populacional e concentrando uma população formada, em geral, por moradores antigos da região.

Para o segundo aspecto da dimensão em análise, que trata da visibilidade da água e abertura do porto, elaboramos perguntas que visavam estimular os entrevistados a pensar o Porto como um espaço urbano aberto para usos culturais, de lazer ou para melhorar a mobilidade urbana.

No percurso da interface física do Porto com a cidade existem quatro aberturas visuais que permitem observar a baía que se esconde atrás dos muros. A primeira possibilita ao passante observar a entrada e saída de veículos, peças e tubos, a empresa Flexibras-Technip. Há dois pequenos vãos entre os antigos armazéns, onde há entulhos e visualiza-se o mar por um rápido olhar. Finalmente, a abertura central, que é a maior e está em frente ao Palácio Anchieta, onde observamos cargas vinculadas à atividade petrolífera, navios ancorados e o passar de pessoas e veículos.

Para os entrevistados, abrir mais espaços para visualização da baía entre os armazéns seria muito bom (51\%), bom (24\%), indiferente $(19 \%)$ e ruim $(7 \%)$. O que nos leva a concluir que há de fato o interesse da população por mais trechos com visualização da baía ou mesmo da atividade portuária. A abertura de mais trechos de visualização da atividade portuária seria uma excelente alternativa para aproximar o dia a dia do porto do dia a dia da cidade e ganhar a atenção dos indiferentes.

Observamos que o Porto é território desconhecido de número expressivo daqueles que convivem diariamente com ele - $44 \%$ dos comerciantes e $32 \%$ dos moradores nunca estiveram no espaço portuário. Dentre aqueles que já visitaram o Porto, $40 \%$ foi por motivação turística, seguidos de $23 \%$ que o fizeram por motivos profissionais. Há, portanto, interesse no Porto como um programa turístico, aspecto que pode ser potencializado para servir como 
canal de aproximação cidade e porto.

Interessante observar que dentro do conjunto dos comerciantes que ainda não visitaram o Porto, $31 \%$ não o fizeram por falta de oportunidade. Por parte dos moradores, apenas $8 \%$ não tiveram oportunidade e $23 \%$ revelam falta de interesse, o que volta a reforçar o afastamento entre os moradores da cidade do Porto.

A falta de conscientização e debate sobre as interfaces cidade e porto pode ser verificado pelo percentual de desconhecimento das propostas da Codesa e do governo do Estado de destruição dos armazéns $(75 \%)^{4}$. Perguntados se seriam a favor, contra ou indiferentes à destruição dos armazéns do Porto para aumento do espaço de armazenagem, 44\% dos comerciantes e $43 \%$ dos moradores são favoráveis. Percebe-se maior percentual contra a derrubada entre os comerciantes (43\%), do que entre os moradores $(34 \%)$, indicando, em um olhar superficial, que os primeiros se identificam mais com os edifícios e armazéns históricos do Porto do que os moradores. Chama atenção a indiferença dos moradores $(23 \%)$, o que reforça a hipótese de desapego ao valor histórico e patrimonial do Porto por parte dos moradores da cidade.

Quando fizemos a pergunta sobre a destruição dos armazéns com finalidade de uso para mobilidade urbana ${ }^{5}$ observamos a elevação do percentual médio daqueles que são a favor - de $43 \%$ para $59 \%$. O posicionamento dos moradores contra a derrubada dos armazéns permaneceu estável independentemente da motivação. Verifica-se uma queda de $44 \%$ para $34 \%$ de comerciantes contra a derrubada dos armazéns, caso a motivação deixe de ser por finalidade da atividade portuária e passe a ser por melhorias na mobilidade urbana. Ou seja, os laços de identidade e valorização patrimonial e cultural dos comerciantes com o Porto não são tão sólidos ou relevantes como a princípio poderia se supor.

\footnotetext{
${ }^{4}$ Há dois projetos de destruição dos armazéns. Um, proposto pela Codesa, para destruir os antigos armazéns construídos para carga a granel e abrir espaços para carga fracionada e, outro, do governo do Estado, para passagem dos corredores do BRT por dentro dos armazéns.

${ }^{5}$ Existe um problema na mobilidade urbana decorrente das poucas saídas da ilha de Vitória para os municípios vizinhos. A entrada de caminhões de carga para o Porto situa-se na entrada da ilha de Vitória para os veículos que vêm de Cariacica e Vila Velha, região onde também há um estreitamento de pista. A movimentação de cargas do Porto utiliza-se do mesmo trajeto que os veículos de passageiros, ocasionando aumento do trânsito na região. Para amenizar os impactos no trânsito, o fluxo de caminhões é restringido pelo Decreto Municipal n.10.364/99 entre $7 \mathrm{hs} / 9 \mathrm{hs}$ e $17 \mathrm{hs} / 19 \mathrm{hs}$, aspecto que é alvo de reclamações por parte da CODESA.
} 
Em relação ao aproveitamento das instalações portuárias para uso urbano, $87 \%$ concordam que a administração portuária deveria permitir que espaços portuários ociosos fossem usados como área para cultura e lazer. Dentre os entrevistados, $65 \%$ conhecem o Projeto Estação Porto, projeto casado entre as Secretarias Municipais de Cultura e de Turismo, que acontece no Armazém 5, com a oferta de shows e atividades culturais. Dado que há considerável divulgação na mídia, é gratuito e acontece desde 2006, é alto o percentual de $35 \%$ de pessoas que desconhecem as atividades culturais que acontecem no Porto.

Enquanto $34 \%$ dos comerciantes não tiveram oportunidade de estar em algum dos eventos do Estação Porto e apenas 7\% não têm interesse, a proporção se inverte ao considerarmos os moradores: $14 \%$ dos moradores não tiveram oportunidade e $25 \%$ não tiveram interesse em participar.

Considerando que essa é a única oportunidade que a população local tem de entrar no espaço portuário ou de vivenciar alguma atividade cultural desenvolvida em parceria cidade e porto, não surpreende que $59 \%$ dos entrevistados consideram o Porto pouco acessível à população. Surpreende, contudo, que o interesse em que o espaço portuário fosse mais acessível à população é maior entre os comerciantes $(82 \%)$ do que entre os moradores (71\%). Cabe ressaltar que $29 \%$ dos moradores são indiferentes ou não têm interesse em ter acesso ao espaço portuário, posicionamento que reforça a percepção do Porto como atividade isolada.

Pensando nas ações dos waterfronts, questionou-se o interesse e foram favoráveis que houvesse no Porto: um mirante para observação das atividades portuárias $(80 \%)$, um museu sobre a história do Porto (86\%), a retomada do transporte aquaviário ligando Vitória/Vila Velha/Cariacica (95\%) e atividades de esporte na baía (92\%). A possibilidade de criação de um museu do Porto foi o único aspecto em que um maior número de comerciantes (10\%) do que de moradores $(5 \%)$ considerou a ideia ruim. Nos demais aspectos, a quantidade de moradores que achou as propostas ruins ou se posicionou como indiferente foi superior ao posicionamento dos comerciantes. Ainda assim, os altos percentuais sugerem que uma política pública de resgate da identidade de cidade portuária através de ações culturais e esportivas poderia contornar os sinais de falta de interesse dos moradores pelo Porto.

Em suma, há interesse da população em ter maior acesso visual à Baía de Vitória, visão que é impedida pelas construções portuárias. O Porto é considerado um local fechado e continua sendo território desconhecido de grande número dos entrevistados. A perpetuação de programações 
turísticas e culturais e a adoção de ações aos moldes dos waterfronts (museu, aquário, mirantes etc.) são bem vistas pela população e poderiam aumentar a integração cidade e porto. Os altos percentuais a favor da derrubada dos armazéns, independentemente dos motivos, apontam para a pouca relevância que a população atribui aos armazéns como patrimônio histórico. Fato que aliado à constatação do desinteresse e mesmo percepção negativa que os moradores apresentaram do Porto são um dos reflexos da perda da identidade de ser cidade portuária.

O terceiro aspecto considerado na dimensão urbana da interface cidadeporto é a exploração das potencialidades da água. Opção tradicional de uso da baía para transporte público são os catraieiros. Atividade tradicional, passada de pai para filho, Vitória conta com cerca de 10 catraieiros que por tarifa módica conduzem pequenos grupos pela baía, ao lado dos grandes navios, no percurso Vitória/Paul ou em passeios ao Penedo. 86\% dos moradores conhecem a atividade dos catraieiros, número que cai para $47 \%$ dos comerciantes. Apesar de $41 \%$ dos entrevistados acharem a atividade muito importante, moradores e comerciantes do Centro não fazem parte do grupo dos maiores usuários, já que apenas 56\% dos moradores e 20\% dos comerciantes fizeram alguma viagem com eles.

Finalmente, incluímos nos questionários perguntas sobre a opinião em relação aos aspectos positivos e negativos da presença do Porto. Como aspectos positivos, destacaram-se na seguinte ordem: crescimento econômico, atração de turistas, simbolismo histórico e cultural e paisagem urbana do Centro. Verifica-se a associação direta do Porto com a atividade econômica - aspecto destacado como o mais importante - e também com a atração de turistas - aspecto vinculado à chegada dos grandes cruzeiros que atracam no Cais Comercial. O simbolismo histórico e cultural foi relegado a segundo plano, ressaltando o pouco peso histórico do Porto na vida da cidade.

Sobre os aspectos negativos, destacam-se na seguinte ordem: falta de segurança, poluição visual, falta de acesso à baía e mobilidade urbana. Os arredores do Porto são inseguros para $75 \%$ da população, o que foi muito lamentado por vários entrevistados. Sua presença física não se insere em percepção de constituição positiva de uma paisagem, tende para uma percepção como poluidor visual.

Quando questionados se as atividades desenvolvidas no Porto têm algum reflexo na qualidade de vida na região, $53 \%$ disseram que sim e positivamente, $33 \%$ disseram que não têm impacto relevante e apenas $14 \%$ disseram que sim e negativamente. Depreende-se que a atividade portuária acontece sem 
que atrapalhe ou incomode a vida na cidade. Acreditamos que a percepção positiva em relação ao Porto está associada ao seu papel na economia, já que $70 \%$ concordam com a essencialidade da atividade do Porto para o desenvolvimento econômico da cidade.

\section{Considerações finais}

A cidade de Vitória nasce com cidade portuária. Porto e cidade desenvolvemse em harmonia por séculos. Seguindo o modelo de Brian Hoyle (1989), identificamos que se segue a este momento outros onde cidade e porto se afastam, se atrapalham e novamente se reencontram.

As políticas e ações gerais da gestão pública municipal e estadual atual deixam em segundo plano a promoção da identidade de ser cidade portuária e, com isso, a história e tradição urbanas vinculadas ao Porto de Vitória têm sido perdidas e esquecidas. O desinteresse e descaso dos habitantes do Centro revelados na pesquisa de campo são reflexos de uma cidade que foi cidade portuária e hoje é muito mais uma cidade porto.

A comunidade do entorno portuário não chega a perceber o Porto com algo que atrapalha, mas, ao contrário, mantém opinião positiva. Entretanto, não tem interesse, apego histórico, identidade ou qualquer sentimento de vínculo. O Porto simplesmente está lá, um vizinho sobre o qual se sabe pouco e se quer saber pouco. Sobretudo os moradores do Centro adotam postura de indiferença ou distanciamento. Ao ouvirmos a voz da cidade portuária de Vitória, identificamos que restam muito pouco da simbiose, complementaridade e integração do ser cidade portuária.

\section{Referências}

LE RÉSEAU MONDIAL DES VILLES PORTUAIRES AIVP.

(2007). Plan the city with the port. Disponivel em: http://www.aivp.org/en/blog/2007/1. Acesso em 06 de agosto de 2013.

BRECIANI, Marcus.

(2010). A Interface Cidade-Porto de Vitória: 0 ponto de vista da Codesa. Vitória, 29 abril de 2010 - 05 maio de 2010. Entrevista concedida a Flavia Nico Vasconcelos.
BIRD, James.

(1963). The major seaports of the United Kingdom. Londres: Hutchison.

CAMPOS, Martha Machado.

(2004). Vazios operativos da cidade: territórios interurbanos na Grande Vitória (ES). Tese de doutorado apresentada à Pontifícia Universidade Católica de São Paulo. 
DUCRUET Cesar.

(2005). Spatial structures and trends in port cities: from the local to the global. Mappemonde, 77(1). Disponivel em: http:// mappemonde.mgm.fr/num5/articles/ art05106.html. Acesso em 22 maio 2010.

HENRY, Magalie.

(2006). Villes portuaires en mutation - Les nouvelles relations ville-port à Marseille dans le cadre du programme de renouvellementurbain Euroméditerranée. Lausanne: Université de Lausanne, Institut de Géographie.

HOYLE, Brian.

(1988). Development Dynamics at the PortCity Interface. In: HOYLE, B. S.; PINDER, D. A.; HUSAIN, M.S. (Eds); Revitalising the Waterfront. Chichester: Wiley.

HOYLE, Brian.

(1997 / 1998). Cities and ports - concepts and issues. Vegueta, n. 3, p. 263-278.

MENEGHEL, Clemir.

A Interface Cidade-Porto de Vitória: o ponto de vista da Secretaria de Desenvolvimento da Cidade (SEDEC). Vitória, 07 julho de 2010. Entrevista concedida a Flavia Nico Vasconcelos.

NORCLIFFE, Glen.; BASSETT, Keith.; HOARE, Tony.

(1996). The emergence of postmodernism on the urban waterfront: Geographical perspectives on changing relationships. Journal of Transport Geography, v. 4, n. 2, p. 123-134.

PRATA, Eduardo.

(2010). A Interface Cidade-Porto de Vitória: o ponto de vista da Codesa. Vitória, 15 junho de 2010. Entrevista concedida a Flavia Nico Vasconcelos.

PREFEITURA MUNICIPAL DE VITÓRIA - PMV.

(2011). Dados da Sinopse - julho de 2011. Disponivel em: http://legado.vitoria.es.gov. br/regionais/Censo_2010/dados_sinopse_ populacao.asp. Acesso em 08 de agosto de 2013.
SIQUEIRA, Maria da Penha Smarzaro; VASCONCELOS, Flavia Nico.

(2012). Urbanização da cidade e nova concepção portuária: a trajetória compartilhada pela cidade e porto de Vitória na construção do progresso e de identidades. Disponível em: http://www.aahe.fahce.unlp.edu.ar/ jornadas-de-historia-economica/iii-cladhexxiii-jhe/ponencias/Penha\%20Nico.pdf . Acesso em 10 de agosto de 2013.

SIQUEIRA, Maria da Penha Smarzaro.

(1995). 0 desenvolvimento do porto de Vitória 1870-1940. Vitória: Codesa.

SOARES, Henrique Amorim; LIMA Jr., Pedro de Novais.

(2005). Argumentos intelectuais e articulações escalares: o debate em torno da revitalização do Porto de Vitória (Brasil). Scripta Nova, v. IX, n. 194 (45). Disponível em: http://www. ub.edu/geocrit/sn/sn-194-45.htm. Acesso em 06 abril de 2011.

VASCONCELOS, Flavia Nico.

(2011). 0 desenvolvimento da interface cidadeporto em Vitória do periodo colonial ao início do século XXI: uma cidade portuária? Tese de doutorado apresentada à Pontifícia Universidade Católica de São Paulo.

WANG, James; OLIVIER, Daniel.

(2003). La gouvernance des ports et la relation ville-port en Chine. Les Cahiers Scientifiques du Transport, $\mathrm{n}^{\circ} 44$.

ZIMMER, Henrique.

(2010). A Interface Cidade-Porto de Vitória: a experiência do ex-diretor da Codesa. Vitória, 24 de maio de 2010. Entrevista concedida a Flavia Nico Vasconcelos.

\section{Recebido em}

abril de 2014

\section{Aprovado em}

agosto de 2014 